\title{
Integrating the weight of history into the alignment framework: the case of distributed generation technologies
}

Thomas Bauwens ${ }^{1}$

\begin{abstract}
Whereas a centralized energy supply system is still dominant today, the energy sector is currently witnessing the development of small-scale and more geographically dispersed generation units, so-called distributed generation technologies. The alignment framework proposes a very useful approach to look at this evolution. Yet, we argue in this paper that this framework does not fully take into account the inertia associated with past technological and institutional choices that may hinder future changes. Relying on the concept of socio-technical lock-in, we illustrate this point with the case of the diffusion of distributed generation technologies. Based on this analysis, we propose an adaptation of the alignment framework to integrate these elements.
\end{abstract}

Keywords: distributed generation, socio-technical system, lock-in, alignment framework, coevolution.

\footnotetext{
${ }^{1}$ Centre, for Social Economy, University of Liege. Bd du Rectorat, 7 (bât. B31), 4000 Liège, Belgique. Tél. : +32 (0) 436637 73. Email : thomas.bauwens@ulg.ac.be.
} 


\section{Introduction}

The energy sector is currently undergoing deep changes compared to its historical configuration, both at the institutional and technological levels. Indeed, whereas a centralized model has been dominant for a long time, this sector is currently witnessing the development, favored by the evolution of ICT, of small-scale and more geographically dispersed generation units, so-called distributed generation technologies. Parallel to this, liberalization processes have been implemented in most developed countries to unbundle the main steps of the value chain that were formerly integrated in one same company.

The so-called alignment framework is a particularly relevant angle to look at these transformations, because it precisely focuses on the institutional and technological changes simultaneously and on the interactions between these two aspects. However, although significant progress has been made on that respect, we argue in the present paper that this framework remains somewhat too static and does not fully take into account the genuine dynamics of institutional and technological evolutions. We suggest that the economic literature concerned with increasing returns to adoption, path-dependence and lock-in effects and, in particular, the concept of "socio-technical lock-in", can usefully contribute to solve this problem. To show this, we apply it to the case of the diffusion of distributed generation (DG) technologies and the various technological and institutional innovations that this process involves.

In section 2, we present the background of the analysis, describing the traditional centralized organization of the energy system and how the liberalization process has dramatically altered this model at the institutional level, while the technological coordination has essentially remained unchanged. Then, we briefly describe what DG technologies are and present their potential benefits, mostly from an environmental point-of-view. Section 3 presents the method that is used and the theories that are mobilized. First, we describe the alignment framework in its static version and describe the efforts made to make it dynamic. Then, we introduce the notion of increasing returns to adoption and explain how the latter can lead to a situation of technological "lock-in". In a third step, we extend this notion of lock-in to a broader spectrum beyond a mere technological vision, relying on the concept of "socio-technical system" and, on this basis, we define the notion of "socio-technical lock-in". In section 4, we apply the latter on the case of the diffusion of distributed generation technologies. To do so, we identify six sources of lock-in. We illustrate each of them with the case of DG. In section 5, we 
conclude and discuss the findings of this analysis and explain the theoretical implications for the alignment framework.

\section{The background}

\subsection{The traditional centralized model and the liberalization process}

At the technological level, the dominant model of energy infrastructure, due to historical and technological reasons, is characterized by large centralized power stations generally located close to sources of fossil fuels and remote from demand, which supply huge grids run by regional or national monopolies. The energy sector has emerged as a vertically and horizontally integrated system with important technical interdependencies (Künneke, 2008). This configuration allowed to benefit from economies of scale, network externalities and other types of increasing returns to adoption, as we will see below.

At the institutional level, before the wave of liberalization that has swept most industrial countries in the last twenty years, the energy sector was historically institutionalized along with this technological configuration, according to a highly hierarchical and centralized organization. It was vertically integrated, which means that firms operating in the different functions of the energy value chain, i.e. production, network activities and sales, were strongly interconnected through ownership rights, contracts and regulation (Künneke, 2008).

Liberalization, in turn, implied, "the decoupling of major parts of the value chain into independent entities" (Finger, Groenewegen et al., 2005: 245). Network related activitiestransmission and distribution-remained subject to sector specific regulation, because they are considered natural monopolies and, therefore, could not be exposed to competitive markets. "On the other hand, production, trade, metering and sales are considered as commercial activities that can be performed under market conditions" (Finger, Groenewegen et al., 2005: $245)^{2}$.

\footnotetext{
${ }^{2}$ In practice, however, although the liberalization process significantly changed the European landscape of the power industry, institutions are still strongly marked by the traditional trajectory. Indeed, according to DTI/Ofgem (2006), the market and regulatory models adopted at privatization reflected the predominantly centralized model of transmission and distribution. In a recent study, Matthes, Grashof et al. (2007) empirically identify different development patterns. While in the UK and Scandinavian countries, power generation is quite competitive and unconcentrated, market concentration in continental Europe remains very high.
} 


\subsection{What are distributed generation technologies?}

While many definitions of distributed generation technologies exist ${ }^{3}$, distributed generation (DG) technologies are, according to the EU Electricity Directive (Communities, 2009), generations units connected to distribution systems. In addition to this criterion, the literature often emphasizes the following basic elements: they are small generation units, typically ranging from less than a $\mathrm{kW}$ to tens of $\mathrm{MW}$, which are geographically dispersed and located close to load centers. In the context of the major environmental challenges linked with climate change and greenhouse gas emissions, it is increasingly recognized that they represent a more sustainable model of power supply, for several reasons (e.g. Goldemberg, Johansson et al., 1988; Johansson, Kelly et al., 1993). First of all, a large segment of the DG market is constituted by combined heat and power production (CHP) units. These units are expected to enhance energy conservation and, subsequently, to reduce $\mathrm{CO}_{2}$ emissions, due to a higher overall efficiency through the simultaneous production of heat and electricity. It is worth mentioning that CHP units are at the moment mostly based on fossil fuels, but they have the potential to be fuelled by renewables in the future. Secondly, while the development of renewable energy sources, such as photovoltaic or wind, appears to be an essential tool in the fight against climate change, most renewables, except for large hydro, have a decentralized nature. Hence, "most government policies that aim to promote the use of renewables will also result in an increased impact of distributed generation technologies" (Pepermans, Driesen et al., 2005: 790). Thirdly, aside from reductions in carbon emissions due to enhanced technological efficiency (in the case of CHP) and zero carbon emissions (in the case of renewables), empirical studies show that DG technologies may also induce a shift in consumption behaviors towards lower levels of energy consumption and through load shifting ${ }^{4}$ by increasing consumers' awareness of their energy use and it impacts (Haas, Ornetzeder et al., 1999; Dobbyn and Thomas, 2005; Bahaj and James, 2007; Keirstead, 2007). Overall, "a system with a large amount of DG is considered an environmentally friendly alternative to the traditional power supply system" (Wolsink, 2012: 823). Figure 1 shows the share of DG in electricity production in European countries.

\footnotetext{
${ }^{3}$ See e.g. Ackermann, Andersson et al. (2001) and Pepermans, Driesen et al. (2005) for discussions.

${ }^{4}$ Load shifting designates the change in the time of energy consumption and, in particular, the transfer of demand from the peak hours to off-peak hours of the day.
} 
Figure 1: DG shares in total electricity generation in EU-25 countries, 2004.

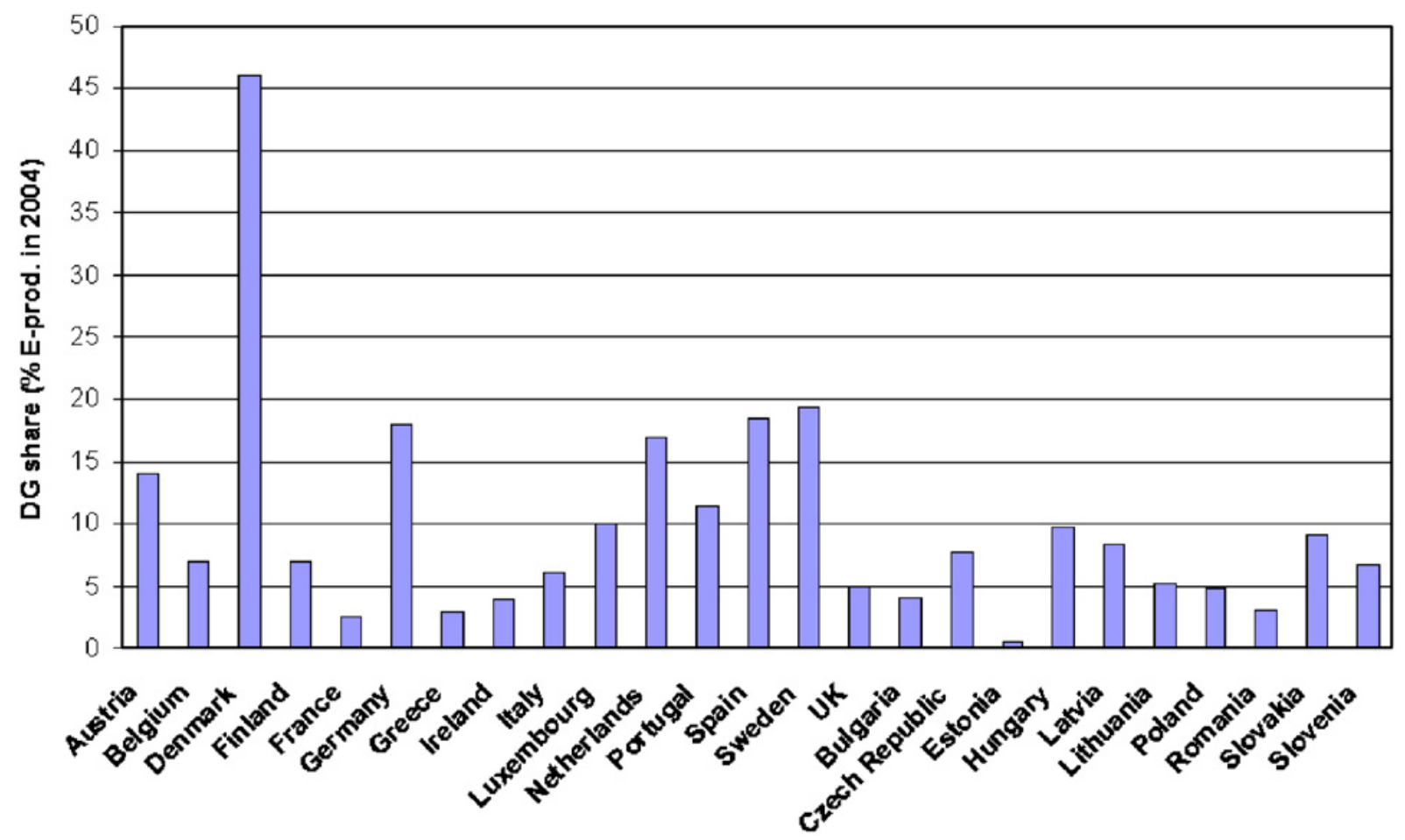

Source: Cossent, Gómez et al. (2009).

As we can see, there are significant differences between countries, which can reflect their different abilities to overcome the barriers impeding the diffusion of DG. Denmark, for instance, is the European country with the highest share of DG (above 45\% in 2004). Consistently, according to Skytte and Ropenus (2005), the regulatory barriers to DG penetration in Denmark are significantly lower than in other European countries ${ }^{5}$.

\section{Theory and methods}

\subsection{Methodological approach}

From the theoretical point-of-view, we heavily rely on the economic analysis of technological evolution and, in particular, on the concepts of increasing returns to adoption, pathdependence and lock-in. However, technology is not an artifact isolated from the rest of social reality. Hence, we advocate an extended vision of the process of lock-in, what we call sociotechnical lock-in, rooted in the concept of socio-technical system. In order to make this theoretical framework applicable, we define socio-technical lock-in as composed of six

\footnotetext{
${ }^{5}$ For a long-term historical analysis of the diffusion of DG technologies in Denmark relying on the concepts of lock-in and regime change, see van der Vleuten and Raven (2006).
} 
empirically identifiable dimensions, extending Unruh (2002)'s analysis: institutional, technological, organizational, industrial, societal and psychological.

We start our analysis by addressing the three basic questions that are central in the alignment framework: 1) What is performance in the context of the energy sector? 2) What is alignment in the context of the energy sector? And 3) Who are the actors involved? Then, we investigate each of the aforementioned dimensions through the case of the diffusion of DG technologies. To do so, we conducted an extensive literature review that enabled to capture the different existing barriers to the diffusion of DG in each dimension. We tried to illustrate these barriers with concrete situations in different European countries.

We proceed to our analysis mostly at a systemic level, seeking to emphasize the links and interactions between the different dimensions rather than an in-depth investigation of one of them $^{6}$. In this sense, our perspective is close to the one promoted by the "Dutch" School of transition researchers (Kemp, Schot et al., 1998; Geels, 2002, 2011; Kemp, 2011), who integrate energy transformations into a larger picture of social, institutional and economic change. This approach is perfectly compatible with the alignment framework, since network industries are conceived in the latter "as complex socio-technical systems in which technological and institutional elements are strongly interwoven" (Crettenand and Finger, 2013: 107).

\subsection{The alignment framework}

The fundamental idea underlying the alignment framework, developed by authors such as Finger, Künneke, Groenewegen, Ménard and Crettenand (Finger, Groenewegen et al., 2005; Künneke and Finger, 2007; Künneke, Groenewegen et al., 2010; Crettenand and Finger, 2013), is that network industries require a certain degree of coherence between institutions and technology in order to ensure a satisfactory level of performance. Indeed, as we have seen through the case of the energy sector, most network industries have undergone a process of liberalization at the institutional level. However, some activities, e.g. the electricity grid,

\footnotetext{
${ }^{6}$ We are conscious, however, of Hård (1993)'s criticism of the socio-technical system approach, according to which the latter tends to over-emphasize the harmonious functional interactions between components and to neglect conflicts and disfunctionality. Consistently, while most of the time increasing returns lead to the domination of a particular socio-technical regime dominates, we do not deny in our approach the possibility of conflicting views between actors and temporary periods of competition between different regimes, as illustrated below by the conflicting co-existence between alternating and continuous current technologies.
} 
remained monopolistic due to technical and economic factors. Consistently, Finger, Groenewegen et al. (2005) claimed that liberalization introduced some incoherence between "a now liberalized institutional environment on the one hand and the current state of the technology on the other" (Crettenand and Finger, 2013: 109). The alignement framework has up to now been applied to industries such as electricity (Künneke, 2008), railways (Künneke and Finger, 2007; Perennes, 2013), air transport (Finger, Groenewegen et al., 2005) or telecommunications (Anker and Lemstra, 2013).

Recent versions of the alignment framework put a particular emphasis on the role of actors in shaping the co-evolution of institutions and technologies. Three categories of actors are distinguished: institutional actors, who are capable of shaping the institutions under which all other actors, including themselves, behave (political authorities, public administrations, regulators). technological actors, who have the capabilities to innovate and develop technologies (R\&D departments in firms, Universities and research labs), and market actors, who provide the services of a given network industry. In this framework, consumers are not explicitly actors as such, but as far as DG technologies are concerned, it is useful to consider consumers in a more active fashion, because they can exert a significant influence on the diffusion of these technologies, becoming in some cases producers themselves -so-called "prosumers"-as we will see below.

Finally, pointing out the fact that the initial version of the framework, as presented by Finger, Groenewegen et al. (2005), was mainly static, Finger, Crettenand et al. (2010) addressed the task of introducing a dynamic perspective within it. Consistently, they argued that network industries can be characterized by three main configurations: 1) public monopoly, either public or private (in the context of so-called public-private partnerships), 2) competition over existing networks and 3) Competition of networks. The dynamics in network industries is thus seen as the shift from one configuration to another and is driven simultaneously by institutional and technological changes. At the institutional level, the driving force is mainly the liberalization process, which tends to disintegrate the traditional centralized authority into unbundled and decentralized entities while, at the technological level, ICTs are the primary driver toward more distributed infrastructures. Figure 2 depicts the co-evolution between institutions and technology as conceptualized in this adapted version of the alignment framework. 
Figure 2: the co-evolution between institutions and technology in the case of network industries

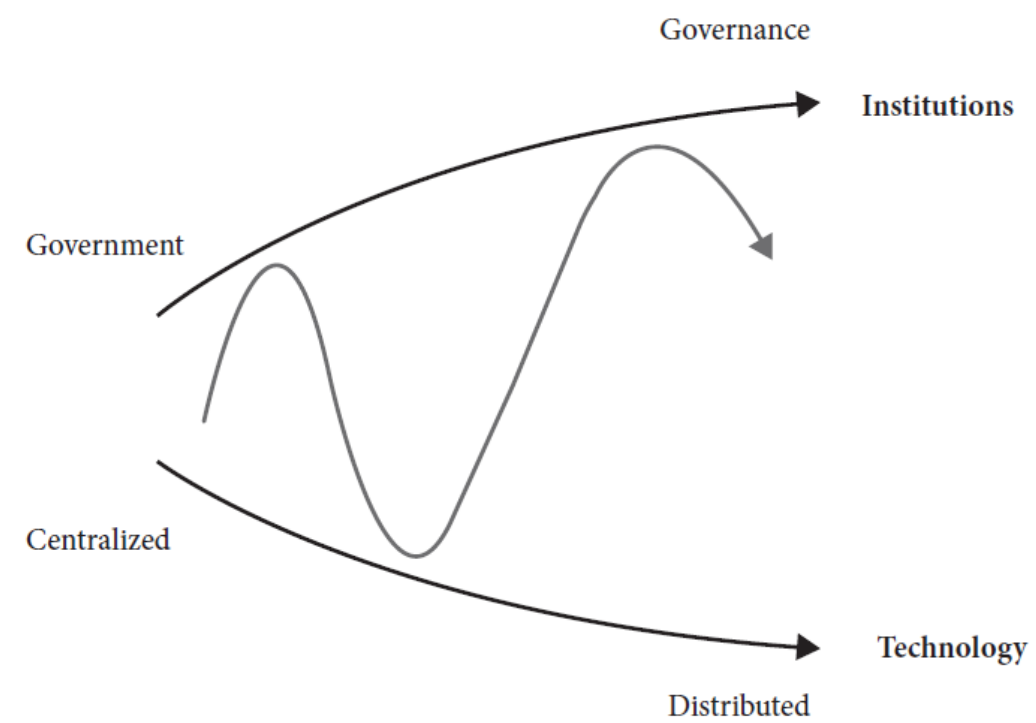

Time

Source: Crettenand and Finger (2013)

However, the dynamic process is not analyzed further. In particular, the transition from one configuration to another implies important costs, which arise from the inertia of past technological and institutional choices and these are not taken into account. Hereafter we review the main works that have explored this question.

\subsection{Introducing increasing returns in the picture}

In their seminal work, whose perspective was mainly technological, David (1985) and Arthur (1989) described the path-dependent process that can lead to market domination of a technology over another. They show, in particular, that this process depends on small historical circumstances and that the winning technology is not necessarily the most efficient one. The cornerstone of this approach lies in the concept of increasing returns to adoption (IRA), which are defined as "positive feedback that increases the attractiveness of a given technology when it is more and more adopted" (Maréchal, 2007).

Four types of IRA are identified in the literature: economies of scale, learning effects, adaptive expectations and network externalities. Economies of scale refer to the decrease in unit production costs associated with the increase in the production volume, while learning 
effects lower the costs as skills and experience increases with the cumulated production (Arrow, 1962). These first two types have been extensively studied by economists, who rely on them to build "learning curves". Adaptive expectations occur as the further adoption of a technology decreases both producers' and purchasers' uncertainty about its general quality and performance (Arthur and Lane, 1991). The last type of increasing returns, so-called "network externalities", refers to the situation in which the benefits of using a technology are positively associated with the number or share of other users of the same technology. These increasing returns create path-dependence in the evolution of technologies, which can eventually generate a lock-in situation.

Examples given in the literature of apparently inferior technologies that have been locked-in as dominant designs include the QWERTY keyboard (David, 1985)-to the expense of superior keyboard designs such as the Dvorak keyboard-, VHS video tape (Arthur, 1990) versus the Betamax technology- and light-water nuclear reactors (Cowan, 1990). It is worth mentioning, however, that the hypothesis according to which path-dependent processes lead to locked-in inferior designs raised strong criticisms (Liebowitz and Margolis, 1990, 1994, 1995). At the heart of this controversy lies the presumed superiority of locked-out technological alternatives, which is intrinsically difficult to prove empirically, what Cowan and Foray (2002) called the problem of the "counterfactual threat".

According to Foray (1997), two periods can be distinguished in all the cases of lock-in processes mentioned above. The initial one is characterized by constant or very low increasing returns. Indeed, as long as the time series is not "long enough for the agent involved to be able to use it to form consistent probability estimates about future possible states of the world", the process is determined by natural preferences, which are themselves historically shaped, rather than by increasing returns, and leads to "a distribution of choices that reflects preferences and which is not influenced by any local or global precedents". Then, in a second period, the system starts exhibiting some dynamic complementarities and positive feedbacks, which tend to reinforce and amplify the initial distribution of choices.

\subsection{An extension of the concept of lock-in}

\subsubsection{The concept of socio-technical system}

It appears more and more clearly that the study of large technical systems and, in particular, the energy industry, should go beyond the mere technological and physical aspects to embrace 
the institutional, social and psychological processes at play (Sauter and Watson, 2007a; Owens and Driffill, 2008). As Hughes (1983: 2) puts it, "Electric power systems made in different societies - as well as in different times - involve certain basic technical components and connections, but variations in the basic essentials often reveal variations in resources, traditions, political arrangements, and economic practices from one society to another and from one time to another. In a sense, electric power systems, like so much other technology, are both causes and effects of social changes".

Starting from the idea that increasing returns do not only arise from a technological perspective, various attempts were made to broaden the concept of technological lock-in consistently with this systemic approach. An important step was made by North (1990), who applied Arthur's analysis to the field of economic and social institutions. He shows that in a world with institutional increasing returns, if markets are imperfect and characterized by substantial transaction costs, inefficient institutional paths can prevail in the long run. Unruh (2000) suggests the notion of techno-institutional complex to capture the interactions between technological systems and public and private institutions. These complexes "emerge through synergistic coevolution initiated by technological increasing returns and perpetuated by the emergence of dominant technological, organizational and institutional designs" (Unruh, 2000: 826). Dosi (1982) goes further and highlights, through the notion of technological paradigm, the existence of lock-ins of ideas, which are "shaped by the cognitive frame of actors and therefore determine exploration frontiers" (Maréchal, 2007: 5187).

In line with this theoretical tradition, we will consider the energy sector as a socio-technical system (STS), defined as "a cluster of interrelated components connected in a network or infrastructure that includes physical, social and informational elements and that thus involves technology, science, regulation, user practices, markets, cultural meaning, infrastructure, production and supply networks" (Maréchal, 2010: 1105). Using the typology of increasing returns presented above, it is worth stressing the peculiar importance of network externalities in this vision in terms of STS, since "they are thought to operate on technological systems that consist not only of multiple interrelated technologies and their supporting infrastructures, but also of technical, informational, economic and institutional relationships that enable them to work together" (Maréchal, 2007: 5187).

\subsubsection{The notion of socio-technical lock-in}


The close interconnections between these different components have important consequences on the development and evolution of STS, particularly for attempts to make rather radical changes to current systems, since such changes are not solely a technical challenge. Indeed, there exist barriers to change of different nature that are necessary to further explore in order to apprehend the dynamics of STS. Applied to STS, the concept of socio-technical lock-in thus designates the combined interaction of technological, institutional, economic and sociocultural forces that mutually reinforce themselves to create inertia in the technological trajectories of our economies. Extending Unruh (2002)'s analysis, we argue that a sociotechnical lock-in can arise from six main sources that are inextricably interconnected: technological, institutional, organizational, industrial, societal and psychological. Consistently with the concept of lock-in, each of these sources may constitute a barrier to the diffusion of DG technologies.

\section{Analysis: an application to the case of the energy sector and the diffusion of distributed generation technologies}

\subsection{What is performance?}

It is difficult to provide a clear-cut definition of performance in network industries, due to the complexity of the relationships between their different components. Initially, Finger, Groenewegen et al. (2005) distinguished three categories of infrastructure performance, namely economic performance, public value and technical integrity. In their attempt to refine this definition of performance, Crettenand and Finger (2013) divided the public value dimension into social and environmental performance and added an operational dimension, which gives the following elements:

- Technical: availability, physical losses (e.g., kWh per $\mathrm{km}$ ), delivered service per capita (e.g., kWh per capita);

- Social: consumer satisfaction, accessibility, affordability, quality of service, safeguarding privacy;

- Operational: reliability/safety, use of the network, congestion;

- Environmental: Greenhouse gas emissions per kWh;

- Economic: price evolution in the sector, subsidies, production costs (costs per $\mathrm{kWh}$ ), productivity. 
On the basis of this element, we suggest that a high-performance energy system could be defined as follows:

Proposition 1: a high-performance energy system is a system characterized by universal access to energy services, combined with security and reliability of supply from efficient, lowcarbon sources.

\subsection{What is alignment?}

As we have seen, liberalization resulted in the unbundling and the decoupling of the institutional governance in the energy sector, while the technical coordination, especially the administration of transmission and distribution systems, is still a regulated monopoly. This leads Finger, Groenewegen et al. (2005: 248) to the conclusion that "prior to liberalization there was a high degree of coherence between the institutional and technical coordination of the sectors activities. Liberalization resulted in a novel institutional structure of the sector, leaving the technical coordination unchanged. Consequently, technical and institutional coordination are incoherent".

Consistently, these authors, along with other scholars advocate the development of a more decentralized and fragmented technological energy system in order to make liberalization successful. As Künneke (2008) puts it, "There are innovative technologies that allow the production of electricity even at the level of private households [...] If this technical development breaks through, a new technical paradigm will occur that would fundamentally change the technological practice of this sector. This would allow for a technical decomposition (i.e. fragmentation) of the electricity system. Obviously, this technological practice would fit much better to the institutional framework of a liberalised market" (Künneke, 2008; italics added). In line with this vision, alignment in the energy sector is defined as follows:

Proposition 2: alignment in the energy sector refers to the evolution of the technological coordination toward a more distributed mode of control to match the liberalized institutional environment ${ }^{7}$. Such alignment implies the multiplication of distributed generation

\footnotetext{
${ }^{7}$ This is the definition of alignment from the technical perspective. It should be noted, however, that alignment can also be seen from the institutional perspective. Alignment would then be defined as the process of recentralization of the institutional coordination, to be coherent with the centralistic technical coordination.
} 
technologies and the parallel technical adaptation of networks to deal with this evolution, in particular the development of so-called "intelligent networks or "smart grids",

\subsection{Who are the actors involved?}

DG technologies may represent important innovative aspects, both at the institutional and technological levels, for a wide range of actors. If we use the vocabulary of the alignment framework presented above, they represent innovations for market actors, such as utilities supplying power generation or electricity network operators, especially distribution network operators. Indeed, these actors will have to deal with the installation of new designs, new network components, a new configuration of the ownership structure, new market entrances, etc. Institutional actors, such as regulators, will be affected, through, for instance, the implementation of incentives to facilitate the integration of DG technologies to networks or the replacement and upgrading of existing network infrastructure. Finally, technological actors will have to deal with new technical challenges involved, for example, by the technical integration of DG to grids, the conception of new metering systems, etc. Finally, a specific role will be by consumers, who will be more actively engaged, while there has historically been very little consumer involvement in energy generation.

Proposition 3: the diffusion of DG technologies affects all the different types of actors: market actors, institutional actors, technological actors, as well as consumers. The number and type of concerned actors depends on the national contexts and the specific market concentration and organization of the different countries.

\subsection{The interest of a historical approach}

In relation with the concept of performance defined above, we have already explained how DG technologies may enhance the environmental performance of energy systems by limiting greenhouse emissions. We will see below that they may also represent technical and regulatory advantages, such as the improvement of power supply or the provision of some ancillary services. However, they also represent a genuine challenge at many levels, precisely due to the aforementioned path-dependent and lock-in processes. Indeed, if they are installed in sufficient numbers, DG technologies could be highly disruptive for current energy systems (Sauter and Watson, 2007a). In turn, their development depends on the willingness to accept

\footnotetext{
${ }^{8}$ Smart grids refer to upgraded electricity grids that use information and communication technologies to optimize generation, distribution and consumption by gathering and acting on information about suppliers' and consumers' behaviors in an automated fashion.
} 
the key aspects of the innovation that they imply among society and its different actors (consumers, producers, network opertators, authorities, etc).

However, despite the innovative nature, in many respects, of such technologies with regard to the conventional centralized model of power generation, the exploration of past events required by an historical approach leads to consider the current support for DG technologies as a "renewed interest for an old locked-out strategy" (Maréchal, 2012: 141) rather than a genuinely new discovery of their benefits. Indeed, during the period 1887-1892, there was an intense rivalry between the proponents of two technologies competing for the electricity supply market, namely Edison's incumbent direct or "continuous" current system (DC) versus Westinghouse's alternating current (AC) technology (Hughes, 1983; David and Bunn, 1988). Both technologies had their own benefits and disadvantages: DC was more efficient, but was distance-constrained for technical reasons linked to voltage drops, while AC enabled to deliver electric power over a much longer distance. AC technology eventually won the market, which led to the emergence of the current model characterized by large centralized generation units located close to fossil fuels supplying huge distribution grids run by regional or national monopolies, whereas "DC technology would have required a more decentralized system of competing local generation and distribution" (Unruh, 2000: 821). In that respect, the case of DG technologies very eloquently illustrates the crucial importance of introducing historical perspectives in economics.

\subsection{The application of the concept of socio-technical lock-in to energy systems}

\subsubsection{The technological dimension}

The basic technological concern involves interconnecting DG without negatively affecting the "conditions of supply that ensure that end-use equipment and infrastructure can operate safely and effectively" (Passey, Spooner et al., 2011), conditions known as "power quality requirements". Distribution networks have not been conceived to deal with the integration of a large number of DG units. For example, traditional centralized power networks involve power flow in one direction only, from higher voltage levels to lower voltage levels, i.e. from power plant to transmission network, to distribution network, to load. Yet a large number of DG installations may significantly change power flows, which can be potentially bidirectional (Dondi, Bayoumi et al., 2002). 
The relation between distributed generation and power quality is ambivalent. On the one hand, distributed generation can contribute to solve specific power quality problems. For instance, in areas where voltage support is difficult, distributed generation can have a positive impact because connecting DG generally leads to a rise in voltage in the network (IEA, 2002). Dondi et al. (2002) also mention the potential positive effects of distributed generation for voltage support and power factor corrections. On the other hand, the connection of a large number of DG raises some important technical issues as far as power quality is concerned. The main ones are the following:

- Voltage fluctuation and regulation, which refers to a change or swing in voltage and affects many consumer devices. This first category of technical issues can be divided into voltage imbalance, voltage rise leading to reverse power flow, and power output fluctuation (Passey, Spooner et al., 2011). DG technologies are concerned by voltage regulation, because they are both affected by voltage fluctuations occurring on the grid and can be the cause of voltage fluctuations themselves.

- System frequency: the frequency is controlled by maintaining a balance between the connected loads and generation and should be kept within very small deviations from the rated value of $50 \mathrm{~Hz}$, because the well-functioning of many industrial and household applications depends on it. The increasing penetration of decentralized power generating units and, in particular, those relying on intermittent energy sources such as wind and solar, makes frequency control more difficult (Passey, Spooner et al., 2011).

- Unintentional islanding: this situation occurs when "distributed generation delivers power to the network even after circuit breakers have disconnected that part of the network from the main grid and associated generators" (Passey, Spooner et al., 2011: 6285). This raises important safety considerations for the repair personnel working on the lines (Pepermans, Driesen et al., 2005), among other problems.

\subsubsection{The institutional dimension}

Institutional features include elements such as "government policy intervention, legal frameworks, departments/ministries" (Unruh, 2002). As far as DG is concerned, the main source of institutional lock-in arises from regulatory frameworks in place and, in particular, regulation of distribution system operators (DSOs) activities. Indeed, the latter are key players in this issue, since DG are directly connected to distribution networks. 
The traditional regulatory scheme for DSOs is a cost of service or rate of return regulation, based on actual audited distribution costs. However, rate of return regulation has been criticized, because it tends to encourage over-investment and does not provide DSOs with incentives to increase efficiency in the distribution activity. Therefore, in the context of liberalized electricity systems, performance based regulation or incentive regulation has been implemented as an alternative. This mechanism accounts for the existent asymmetries of information between the regulator and the utilities and aims at promoting efficiency in the long-term by indexing the remuneration of distribution to the service provided instead of incurred costs. Incentive regulation has already been implemented in a majority of EU member states as a remuneration scheme for DSOs (Cossent, Gómez et al., 2009).

Financial barriers: there are two different kinds of network charges: connection charges, which are paid only once to compensate for the costs of connection to the network, and useof-system (UoS) charges, that are regularly paid by network users, mostly consumers. As regards connection charges, three different schemes are identified: deep, shallow and shallowish. In the deep charge approach, DG bears all the network reinforcement costs, whereas under shallow and shallowish charges, DG needs to pay only the reinforcement costs within the immediate area, or even not at all. The use of deep connection charges is seen as a major barrier of entry for small-sized DG developers (Skytte and Ropenus, 2005). A recommendation would be to switch to shallower connections charges and to socialize reinforcement costs among the network users through UoS charges. While the majority of EU-15 member states have adopted shallow connection charges, most new member states still present deep connection charges (Cossent, Gómez et al., 2009).

Another financial barrier for the development of DG lies in imbalance penalties (Skytte and Ropenus, 2005). As many renewable-based and CHP DG projects are characterized by the intermittency and non-dispatchability of power generation, they may suffer financial penalties if energy supply and demand do not match, which can prevent them from entering from wholesale markets. This problem does not arise in the case of a small project that is part of the generating portfolio of large, vertically integrated utilities, since these risks can be balanced within this portfolio. "However, independently owned projects face high transaction costs and imbalance risks, and therefore tend to sell output to a third party, usually an electricity supplier. This does not necessarily remove the risk of imbalance penalties, as the third party is likely to offer a price that factors in the impact of imbalance changes on its own market participation" (Woodman and Baker, 2008: 4528). The case of the UK is a good illustration of 
this problem: current market arrangements in this country-called British Electricity Trading and Transmission Arrangements (BETTA)- were conceived according to the characteristics of conventional generation and aim at rewarding dispatchable output. This can favor centralized generation to the detriment of small-scale and unpredictable generators because, on the one hand, emphasis is made on costs, which creates incentives to pursue economies of scale in both generation and trading and, on the other hand, because BETTA requires generators to predict output in advance (Woodman and Baker, 2008).

Lack of incentives: there are several important aspects as far as incentive mechanisms are concerned. First, the aforementioned technological challenges associated with the multiplication of DG technologies imply upgrading, reinforcing or replacing the current network assets. This, in turn, requires departing from the traditional "fit and forget" approach, i.e. the passive network operation philosophy, and considering distribution grids in a more active way. As Frías, Gómez et al. (2009: 446) put it, "If an active network management philosophy is adopted, the amounts of DG that can be accommodated with limited investments will be larger". However, the current regulatory framework offers little incentive for DSOs to accomplish this work. For instance, most of the revenue of DSOs comes from charging consumers, and only a small part from UoS charges paid by DG connected to their networks. This can lead to a situation where DSOs are not encouraged to connect DG to their networks (Woodman and Baker, 2008).

Yet DG installations do not only represent extra costs for DSOs. Indeed, DG can enable DSOs to avoid investments in new network infrastructure, due to the fact that DG is "connected close to end consumers or even on their side of the meter, thus reducing the net demand to be supplied through transmission and distribution grids" (Cossent, Gómez et al., 2009: 1149). This potential of DG to replace network reinforcement has been acknowledged in the Engineering Recommendation P2/6. However, current regulatory mechanisms do not encourage DSOs to take advantage of this opportunity. Indeed, cost of service regulation does not trigger DSOs to exploit potential DG benefits for an efficient network expansion. As Woodman and Baker (2008: 4529) explain it, a DSOs "capital expenditure on equipment increases its regulatory asset base, and therefore the level of returns that it is eligible for in future". It will thus be more profitable for a DSO to spend on its own infrastructure than avoiding reinforcement costs by connecting a DG installation to part of the grid. Implementing incentive regulation is a necessary condition to solve this problem, but might not be sufficient by itself (Frías, Gómez et al., 2009). 
Finally, DG can provide a range of ancillary services that could help DSOs improve the efficiency of the network, like frequency regulation, voltage control... But, again, the regulatory framework needs to be adapted in order to provide the right incentives for taking advantages of these benefits from DG. For instance, an economic compensation for DG should be provided in exchange of ancillary services they offer. The relationships between DSOs and DG developers are also likely to be altered.

Lack of unbundling: as we mentioned in section 2, unbundling requirements are an essential part of the liberalization process in the energy sector. "Yet the effectiveness of unbundling is highly dependent on their actual enforcement by the [member states]. A lack of unbundling in distribution may negatively impact the access conditions for new DG” (Cossent, Gómez et al., 2009: 1151). For competition in generation to be effective, fairness and non-discrimination in network access should be guaranteed, all the more since networks are natural monopolies. This requires overcoming asymmetric information and anticompetitive behaviour created by DSOs. If ownership unbundling is not reinforced, there may be a risk of cross-subsidies between the competitive spheres and the regulated network activity, at the expense of new DG operators. Moreover, DSOs could favour their own DG units or those owned by their previously affiliated companies, for instance, for the computation of the connection charges.

\subsubsection{The industrial and organizational dimensions}

Lock-in may also arise at the industrial and organizational levels. Generally speaking, while incumbent companies are typically good at generating incremental innovations that enhance and consolidate the present order, they typically show much less ability to create superior innovations that could threaten their existing products and know-how accumulated through learning-by-doing and learning-by-using (Tushman and Anderson, 1986; Van de Ven, 1986). In this context, management efforts are routinized through the emergence of standard operating procedures (Nelson and Winter, 1982) and focus on technologically incremental programs, such as total quality management, standardization of procedures, etc (Unruh, 2000). This dominant design is enforced at the industry-wide level, due to the existence of network externalities and coordination effects that often require the creation of codified standards and conventions (Könnölä and Unruh, 2007).

Energy distribution does not escape this phenomenon, since "DSOs are usually risk adverse to make investments on new technologies that are not mature enough" (Cossent, Gómez et al., 
2009: 1150). To achieve the aforementioned network transformations necessary to the connection of a large number of DG units, DSOs need to support innovation. In a sense, performance based regulation by itself encourages innovation, since any improvement in efficiency achieved during the whole regulatory period will benefit DSOs. Yet the length of regulatory periods does not generally exceed 5 years, whereas efficiency gains from $R \& D$ expenditures are not always realized in the short-term. In addition, incentive regulation triggers DSOs to reduce costs as much as possible, including innovation costs. Hence, an adaptation of regulatory mechanisms appears to be necessary to foster innovation. What is more, despite the potential benefits in terms of ancillary services provided by DG mentioned above, most DSOs see DG projects primarily as a source of problems for network management and quality of supply, mainly because of the lack of controllability and observability of these units and "their frequent disconnections in case of network disturbances" (Frías, Gómez et al., 2009: 448).

\subsubsection{The societal dimension}

At the societal level, it can be argued that, alongside technology and institutions, actors' behavior is shaped by systems of socio-cultural norms and representations. In this perspective, it has been suggested that "The symbolic value of [large technical systems] has played an important role in the construction process of national electricity systems" (Sauter and Watson, 2007a: 113). For instance, van der Vleuten (2004) has argued that the development of large hydropower stations has contributed to the consolidation of Swedish national identity. Another example is given by French nuclear plants, which have participated to the idea of "grande nation" and the building of French nationalism (Hecht, 1998).

\subsubsection{The psychological dimension}

These five sources of inertia can be described as structural or collective, since they arise at a supra-individual level. Following Maréchal (2010), we can we add a sixth dimension, which concerns the individual level: the psychological and behavioral components, which refer to the cognitive and psychological factors that open up, or close down, opportunities for the development of new physical or social technologies.

To understand this, it should be noted, first of all, that the installation of DG technologies potentially implies new roles for consumers, who may be actively involved in the energy production and, therefore, become "prosumers" or "co-providers" of energy services (van 
Vliet and Chappells, 1999; Chappells, Klintman et al., 2000). Indeed, while the construction of large technology projects and infrastructures like central power plants usually necessitates a rather passive consent by local communities and by the public in general, DG technologies, in turn, require a more active approval by individuals, in terms of willingness to provide space for the installations of these technologies, capital investments and behavioral changes in energy consumption. In other words, DG technologies require "households' acceptance in terms of both positive public and private attitudes to achieve market up-take of these technologies" (Sauter and Watson, 2007b: 2772). This is particularly true for microgeneration technologies, such as photovoltaics, micro-wind turbines and micro-CHP. If consumers are unaware of the existing micro-generation options, they are unlikely to create the demand required for this market to develop and grow (DTI/Ofgem, 2006). But it is also true for technologies at the community level, such as onshore wind turbines, because the willingness to provide space for their installation depends on people's attitudes towards these technologies. Wind turbines have been the technology most subject to contention to date (Devine-Wright, 2007b). Wind power development has provoked considerable opposition in many places, due to impacts on natural landscapes, which can, in turn, affect tourism, the generation of noise pollution and the negative consequences for property prices and local fauna and flora (Warren and McFadyen, 2010).

Yet the traditional configuration of the energy sector may hinder the development of these more active roles played by consumers. Indeed, far from taking place in a social vacuum, energy-related behavior relies on an " "established infrastructure of taken-for-granted hardware or technological systems" (Shove and Warde, 1998, cited in Owens and Driffill, 2008). In this perspective, it can be argued that the traditional centralized model has enforced a "deficit" view of the public as energy users, "separated from, and minimally engaged in, energy systems over and above pressing a light switch. This has led to the design and deployment of a range of energy technologies, services and procedures, from meters to bills to regulatory institutions to power stations, that foster minimal public engagement" (Devine-Wright, 2007a: 68). From a supply-side perspective, it has led "designers, developers and installers of new energy technologies [to] aim to minimize public engagement since this would be assumed to increase the risk of resistance, delay, planning refusal and inefficient or incorrect use of technologies" (Devine-Wright, 2007a: 69). Verbong, Beemsterboer et al. (2013) also identified several barriers to user engagement in smart grid projects. 
Indubitably, this phenomenon is enforced by the limits of human cognition, what economists have usually called bounded rationality (Simon, 1955). Relying on the concept of habits, which can be defined as context-dependent forms of socially acquired automaticity, Maréchal (2010), following Barnes, Gartland et al. (2004), suggests the notion of "behavioral lock-in" to describe the inertia that generally characterizes individuals' domestic energy practices. Indeed, while habits free up cognitive resources for more strategic issues, they may be at the root of conservative behavior. In line with this idea, insights from behavioral economics and social psychology show that people rely on a range of cognitive and emotional heuristics to make their decisions related with energy consumption and investments (see Baddeley (2011), McNamara and Grubb (2011) or Pollitt and Shaorshadze (2011) for extensive reviews) . For instance, based on a survey among households, Kempton and Montgomery (1982) highlight the use by consumers of simple rules of thumb to assess their energy consumption, which result in systematic underinvestment in energy-efficient assets. What is more, these decisions are often subject to systematic biases. As an illustration, the endowment effect (Thaler, 1980), i.e. the tendency of individuals to valuate goods they already own more than goods they do not, leads households to be reluctant to replace appliances they currently have, even if it is efficient to do so.

Hence, according to a process of "circular causation" or positive feedback loop, habits tend to reinforce the present socio-technical system. Just like institutions evolve along with technology, structural factors, such as technology and institutions, co-evolve simultaneously with individual preferences in a mutually reinforcing fashion. As Maréchal and Lazaric (2012: 70) put it, "while choices in energy consumption are being strongly influenced by the existing carbon-based STS, they, in turn, contribute to reinforce and maintain the incumbent STS".

Figure 3 schematizes the process through which these six dimensions contribute to enforce the socio-technical factors and the six sources that contribute to the socio-technical lock-in in the energy sector. 
Figure 3 :

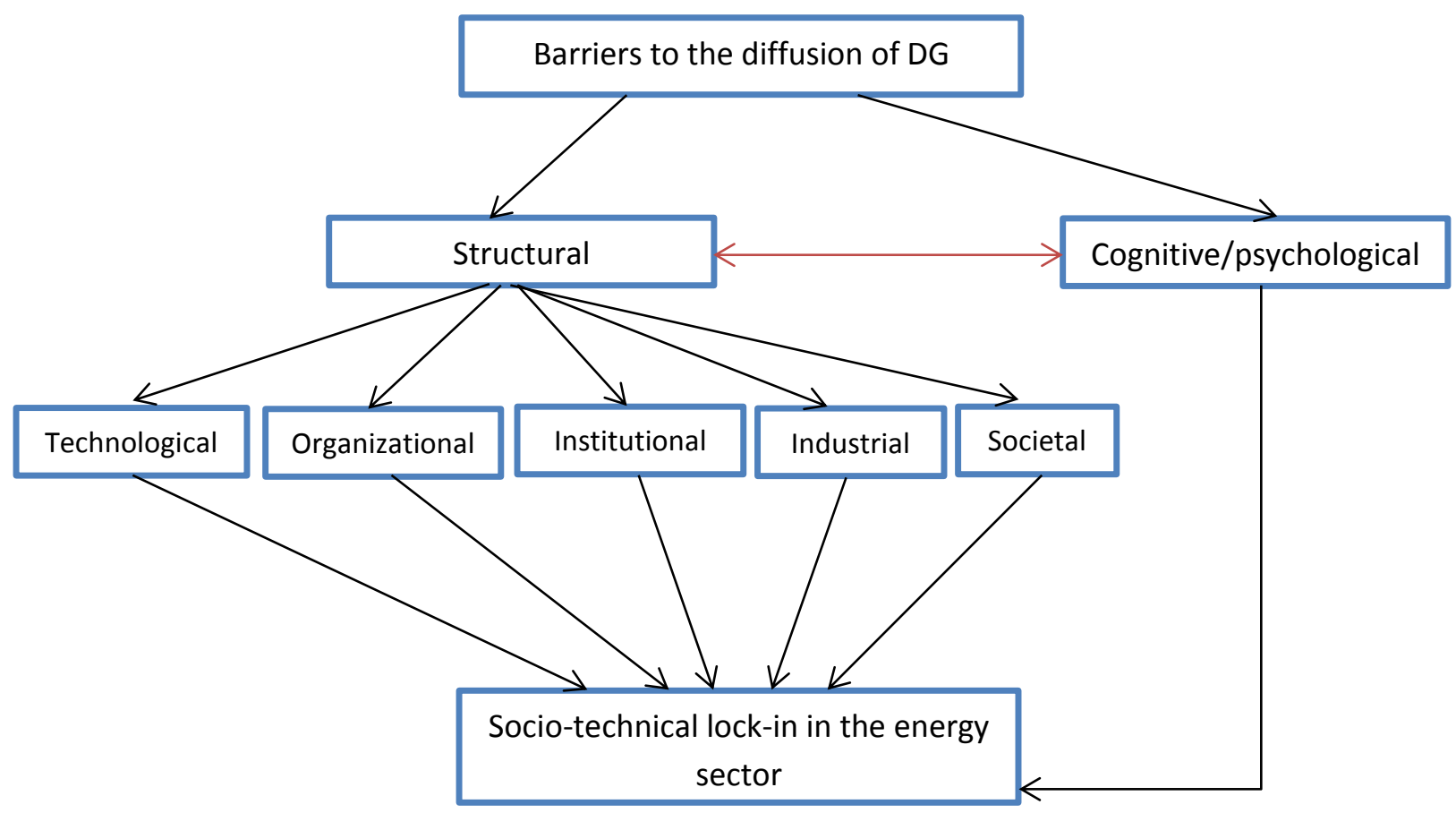

Source: created by the author.

\section{Discussion and conclusions: what are the implications for the alignment framework?}

The present article sought to emphasize the need to take the weight of history into account in the study of the co-evolution of institutions and technologies. We relied on the concept of socio-technical lock-in, which results from the interaction of various dynamics of increasing returns to adoption at the institutional and technological levels. We illustrated this process through the case of distributed generation technologies and identified various barriers to their diffusion. This has direct implications for the alignement framework, because the latter does not enough account for these historical factors in its current version. An updated version would make explicit the inertia linked to past choices and the costs associated with technological and institutional change, as suggested by figure 4 below: 
Figure 4: the co-evolution between institutions and technology in network industries, including the forces of inertia that hinder alignment

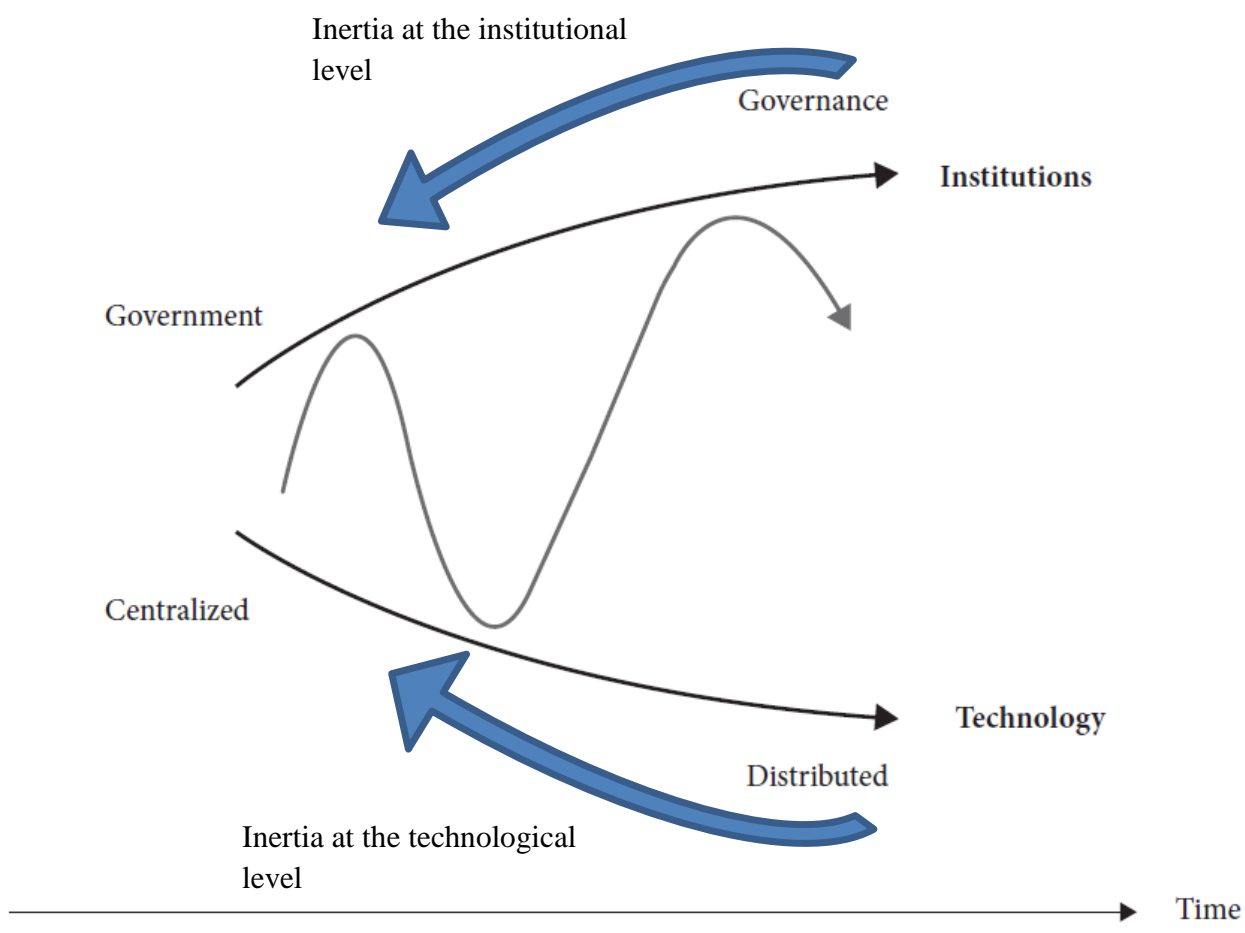

Source: adapted from Crettenand and Finger (2013)

A future research agenda suggested by this study might include an application of this analysis to other network industries and/or other technologies, as well as more in-depth and detailed case studies focused on individual countries.

\section{References}

ACKermann, T., ANDERsson, G., et al. (2001) "Distributed generation: a definition", Electric Power Systems Research, 57 (3): 195-204.

ANKER, P. and LEMSTRA, W. (2013) "Achieving Alignment between Institutions and Technology, the Case of Radio Spectrum", Competition and Regulation in Network Industries (CRNI), 14 (2): 151-173.

ARrow, K. J. (1962) "The Economic Implications of Learning by Doing", The Review of Economic Studies, 29 (3): 155-173.

Arthur, B. and LANe, D. (1991) Information Constriction and Information Contagion. Santa Fe: Santa Fe Institute.

ARthuR, B. W. (1988) "Self-Reinforcing Mechanisms In Economics", In P. W. Anderson, K. J. Arrow and D. Pines (eds), The Economy As An Evolving Complex System. Reading: AddisonWesley.

Arthur, B. W. (1990) "Positive feedbacks in the economy", Scientific American, 262 (2): 92-99.

ARTHUR, W. B. (1989) "Competing Technologies, Increasing Returns, and Lock-In By Historical Events", Economic Journal, 99 (394): 116-131. 
BADDELEY, M. (2011) Energy, the Environment and Behaviour Change: A survey of insights from behavioural economics. Cambridge Working Papers in Economics Cambridge: University of Cambridge, Faculty of Economics.

BAHAJ, A. S. and JAMES, P. A. B. (2007) "Urban energy generation: The added value of photovoltaics in social housing", Renewable and Sustainable Energy Reviews, 11 (9): 2121-2136.

Barnes, W., Gartland, M., et al. (2004) "Old Habits Die Hard: Path Dependency and Behavioral Lock-in", Journal of Economic Issues (Association for Evolutionary Economics), 38 (2): 371 377.

Chappells, H., Klintman, M., et al. (2000) Domestic Consumption Utility Services and the Environment. Final Report of the DOMUS Project.

Communities, E. (2009) Directive2009/72/EC Concerning Common Rules for the Internal Market in Electricity and Repealing Directive 2003/54/EC.

Cossent, R., Gómez, T., et al. (2009) "Towards a future with large penetration of distributed generation: Is the current regulation of electricity distribution ready? Regulatory recommendations under a European perspective", Energy Policy, 37 (3): 1145-1155.

CowAN, R. (1990) "Nuclear Power Reactors: A Study in Technological Lock-in", The Journal of Economic History, 50 (3): 541-567.

COWAN, R. and FORAY, D. (2002) "Evolutionary economics and the counterfactual threat: on the nature and role of counterfactual history as an empirical tool in economics", Journal of Evolutionary Economics, 12 (5): 539-562.

CRetTEnAND, N. and Finger, M. (2013) "The Alignment between Institutions and Technology in Network Industries", Competition and Regulation in Network Industries (CRNI), 14 (2): 106130.

DAVID, P. A. (1985) "Clio and the Economics of QWERTY", American Economic Review, 75 (2): 332.

DAVID, P. A. and BUNN, J. A. (1988) "The economics of gateway technologies and network evolution: Lessons from electricity supply history", Information Economics and Policy, 3 (2): 165-202.

Devine-Wright, P. (2007a) "Energy Citizenship: Psychological Aspects Of Evolution In Sustainable Energy Technologies", In J. Murphy (ed.), Governing Technology for Sustainability. London: Earthscan. pp. 63-86.

Devine-Wright, P. (2007b) Reconsidering Public Attitudes and Public Acceptance of Renewable Energy Technologies: a Critical Review. Manchester: University of Manchester.

Dobbyn, J. and Thomas, G. (2005) Seeing the light: the impact of micro-generation on our use of energy. London: Sustainable Development Commission.

DONDI, P., BAYOUMI, D., et al. (2002) "Network integration of distributed power generation", Journal of Power Sources, 106 (1-2): 1-9.

Dosi, G. (1982) "Technological paradigms and technological trajectories: A suggested interpretation of the determinants and directions of technical change", Research Policy, 11 (3): 147-162.

DTI/OFGEM (2006) A call for evidence for the review of barriers and incentives to distributed electricity generation, including combined heat and power.

FInGER, M., Crettenand, N., et al. (2010) Governing the dynamics of network industries. MIR Working Paper. Lausanne, Switzerland: Ecole Polytechnique Fédérale de Lausanne (EPFL).

Finger, M., GRoEnEwegen, J., et al. (2005) "The Quest for Coherence Between Institutions and Technologies in Infrastructures", Competition and Regulation in Network Industries (CRNI), 6 (4): 227-260.

FORAY, D. (1997) "The dynamic implications of increasing returns: Technological change and path dependent inefficiency", International Journal of Industrial Organization, 15 (6): 733-752.

FRÍAS, P., GÓMEZ, T., et al. (2009) "Improvements in current European network regulation to facilitate the integration of distributed generation", International Journal of Electrical Power \& Energy Systems, 31 (9): 445-451.

GEELS, F. W. (2002) "Technological transitions as evolutionary reconfiguration processes: a multilevel perspective and a case-study", Research Policy, 31 (8-9): 1257-1274.

GEELS, F. W. (2011) "The multi-level perspective on sustainability transitions: Responses to seven criticisms", Environmental Innovation and Societal Transitions, 1 (1): 24-40. 
GoldemberG, J., JohAnsson, T. B., et al. (1988) Energy for a sustainable world. New Delhi, India: Wiley Eastern.

HAAS, R., ORNETZEDER, M., et al. (1999) "Socio-Economic Aspects Of The Austrian 200 KwpPhotovoltaic-Rooftop Programme", Solar Energy, 66 (3): 183-191.

HÅRD, M. (1993) "Beyond Harmony and Consensus: A Social Conflict Approach to Technology", Science, Technology, \& Human Values, 18 (4): 408-432.

HeCHT, G. (1998) The Radiance of France: Nuclear Power and National Identity after World War II. Cambridge: The MIT Press.

Hughes, T. (1983) Networks of Power : Electrification in Western Society, 1880-1930. Baltimore and London: The Johns Hopkins University Press.

Johansson, T. B., Kelly, H., et al. (1993) Renewable Energy: Sources for Fuels and Electricity. Washington D.C.: Island Press.

KeIRSTEAD, J. (2007) "Behavioural responses to photovoltaic systems in the UK domestic sector", Energy Policy, 35 (8): 4128-4141.

KeMP, R. (2011) "The Dutch Energy Transition Approach", In R. Bleischwitz, P. J. J. Welfens and Z. Zhang (eds), International Economics of Resource Efficiency. Physica-Verlag HD. pp. 187213.

KEMP, R., SCHOT, J., et al. (1998) "Regime shifts to sustainability through processes of niche formation: The approach of strategic niche management", Technology Analysis \& Strategic Management, 10 (2): 175-198.

KEMPTON, W. and MONTGOMERY, L. (1982) "Folk quantification of energy", Energy, 7 (10): 817-827.

KÖNNÖLÄ, T. and UNRUH, G. C. (2007) "Really changing the course: the limitations of environmental management systems for innovation", Business Strategy and the Environment, 16 (8): 525537.

KÜNNEKE, R. and FINGER, M. (2007) "Technology Matters: The Cases of the Liberalization of Electricity and Railways", Competition and Regulation in Network Industries (CRNI), 8 (3): 303-336.

KÜNNEKE, R., GroENEWEGEN, J., et al. (2010) "Aligning modes of organization with technology: Critical transactions in the reform of infrastructures", Journal of Economic Behavior \& Organization, 75 (3): 494-505.

KÜNNEKE, R. W. (2008) "Institutional reform and technological practice: the case of electricity", Industrial \& Corporate Change, 17 (2): 233-265.

Liebowitz, S. J. and MARGOlis, S. E. (1990) "The Fable of the Keys", Journal of Law and Economics, 33 (1): 1-25.

LiebowitZ, S. J. and MARGOLIS, S. E. (1994) "Network Externality: An Uncommon Tragedy", The Journal of Economic Perspectives, 8 (2): 133-150.

LiebowitZ, S. J. and MARGOLIS, S. E. (1995) "Path Dependence, Lock-in, and History", Journal of Law, Economics, \& Organization, 11 (1): 205-226.

MARÉCHAL, K. (2007) "The economics of climate change and the change of climate in economics", Energy Policy, 35: 5181-5194.

MARÉCHAL, K. (2010) "Not irrational but habitual: The importance of "behavioural lock-in" in energy consumption", Ecological Economics, 69 (5): 1104-1114.

MARÉCHAL, K. (2012) The Economics of Climate Change and the Change of Climate in Economics. London \& New York: Routledge.

MARÉCHAL, K. and LAZARIC, N. (2012) "Changing habits and routines in energy consumption: how to account for both individual and structural influences while integrating the motivational dimension", The Economics of Climate Change and the Change of Climate in Economics. London \& New York: Routledge.

Matthes, F. C., Grashof, K., et al. (2007) Power Generation Market Concentration in Europe 1996-2005. An Empirical Analysis. Berlin: Öko-Institut e.V.

MCNamara, S. and GrubB, M. (2011) The Psychological Underpinnings of the Consumer Role in Energy Demand and Carbon Abatement. EPRG Working Paper 1110/Cambridge Working Paper in Economics CWPE 1126. Cambridge: Electricity Policy Research Group/Faculty of Economics,University of Cambridge. 
Nelson, R. and WinteR, S. (1982) An evolutionary theory of economic change. Boston: Belknap Press of Harvard University Press.

NORTH, D. (1990) Institutions, Institutional Change and Economic Performance. Cambridge: Cambridge University Press.

OWENS, S. and DRIFFILL, L. (2008) "How to change attitudes and behaviours in the context of energy", Energy Policy, 36 (12): 4412-4418.

PASSEY, R., SPOONER, T., et al. (2011) "The potential impacts of grid-connected distributed generation and how to address them: A review of technical and non-technical factors", Energy Policy, 39 (10): 6280-6290.

PePERMANS, G., DRIESEN, J., et al. (2005) "Distributed generation: definition, benefits and issues", Energy Policy, 33 (6): 787-798.

PerenNeS, P. (2013) "Need for Coherence between Institutions and Technologies: The Example of Uncertain Train Paths in France", Competition and Regulation in Network Industries (CRNI), 14 (2): 130-151.

POllitT, M. G. and ShaOrShadZE, I. (2011) The Role of Behavioural Economics in Energy and Climate Policy. EPRG Working Paper 1130/Cambridge Working Paper in Economics CWPE 1165. Cambridge: Electricity Policy Research Group/Faculty of Economics,University of Cambridge.

SAUTER, R. and WATSON, J. (2007a) "Micro-Generation: A Disruptive Innovation for the UK Energy System?", In J. Murphy (ed.), Governing Technology for Sustainability. London: Earthscan.

SAUTER, R. and WATSON, J. (2007b) "Strategies for the deployment of micro-generation: Implications for social acceptance", Energy Policy, 35 (5): 2770-2779.

Simon, H. A. (1955) "A Behavioral Model of Rational Choice", The Quarterly Journal of Economics, 69 (1): 99-118.

SKYTTE, K. and ROPENUS, S. (2005) Assemssment and recommendations. Overcoming in Short-Term Grid System Regulatory and other Barriers to Distributed Generation. European Commission, Directorate-General for Energy and Transport.

THAlER, R. (1980) "Toward a positive theory of consumer choice", Journal of Economic Behavior \& Organization, 1 (1): 39-60.

Tushman, M. L. and ANDERSON, P. (1986) "Technological Discontinuities and Organizational Environments", Administrative Science Quarterly, 31 (3): 439-465.

UnRUH, G. C. (2000) "Understanding carbon lock-in", Energy Policy, 28 (12): 817-830.

UnRuH, G. C. (2002) "Escaping carbon lock-in", Energy Policy, 30 (4): 317-325.

VAN DE Ven, A. H. (1986) "Central Problems in the Management of Innovation", Management Science, 32 (5): 590-607.

VAN DER VLEUTEN, E. (2004) "Infrastructures and Societal Change. A View from the Large Technical Systems Field", Technology Analysis \& Strategic Management, 16 (3): 395-414.

VAN DER Vleuten, E. and RAVEN, R. (2006) "Lock-in and change: Distributed generation in Denmark in a long-term perspective", Energy Policy, 34 (18): 3739-3748.

VAN VLIET, B. and CHAPPELLS, H. (1999) "The co-provision of utility services : resources, new technologies \& consumers", In: Reader ESF Summer School Consumption, Everyday Life and Sustainability, Lancaster 21-26 August 1999 - Lancaster : Centre for Sciences Studies : Lancaster University, 1999.

Verbong, G. P. J., BEemSTERbOER, S., et al. (2013) "Smart grids or smart users? Involving users in developing a low carbon electricity economy", Energy Policy, 52 (0): 117-125.

WARREN, C. R. and MCFADYEN, M. (2010) "Does community ownership affect public attitudes to wind energy? A case study from south-west Scotland", Land Use Policy, 27 (2): 204-213.

WolsinK, M. (2012) "The research agenda on social acceptance of distributed generation in smart grids: Renewable as common pool resources", Renewable and Sustainable Energy Reviews, 16 (1): 822-835.

WOODMAN, B. and BAKER, P. (2008) "Regulatory frameworks for decentralised energy", Energy Policy, 36 (12): 4527-4531. 